\title{
Is an Intergenerational Program Effective in Increasing Social Capital among Participants? A Preliminary Study in Korea
}

\author{
Junghyun Kim ${ }^{1}$ (1) and Soondool Chung ${ }^{2, *}$ \\ 1 Policy Research Department, Seoul Welfare Foundation, Seoul 04147, Korea; jhkim@welfare.seoul.kr \\ 2 Department of Social Welfare, Ewha Womans University, Seoul 03760, Korea \\ * Correspondence: sdchung@ewha.ac.kr; Tel.: +82-2-3277-4102
}

check for updates

Citation: Kim, J.; Chung, S. Is an Intergenerational Program Effective in Increasing Social Capital among Participants? A Preliminary Study in Korea. Sustainability 2022, 14, 1796. https://doi.org/10.3390/ su14031796

Academic Editors: Kerstin Nilsson, Tove Midtsundstad, Peter Lundqvist, Joanne Crawford, Nygård ClasHåkan and Marc A. Rosen

Received: 24 October 2021 Accepted: 2 February 2022 Published: 4 February 2022

Publisher's Note: MDPI stays neutral with regard to jurisdictional claims in published maps and institutional affiliations.

Copyright: (C) 2022 by the authors. Licensee MDPI, Basel, Switzerland. This article is an open access article distributed under the terms and conditions of the Creative Commons Attribution (CC BY) license (https:// creativecommons.org/licenses/by/ $4.0 /)$.

\begin{abstract}
The rapid growth of the aging population and low economic growth have intensified generational conflicts, especially in the workplace. Social capital is one option that can solve generational conflicts by encouraging cooperation among colleagues. This study aims to explore the impact of the intergenerational program, Sedae Ieum Madang, on perceived social capital among participants in Korea. To measure the impact of the program, a one-group pretest/posttest design was applied, and a purposive sampling method was adopted to recruit participants. The final sample size was 53, including 30 older adults and 23 young adults. In items that measured participants' level of trust in colleagues, the subindex of social capital was compared between before and after the program. Each item relates to peoples' experience of social support in workplaces, as suggested in the swAge model. According to the measurement, peoples' level of trust in their colleagues changed; only the older generation's trust in their colleagues increased, while that of the younger generation did not. The results of this study show that the intergenerational program is effective in encouraging the older generation to trust their colleagues and fostering mutual support between younger and older generations, which is important in developing sustainable work environments.
\end{abstract}

Keywords: intergenerational program; swAge; social capital; trust in colleagues

\section{Introduction}

Korean culture is strongly influenced by the Confucian ethic of filial piety, which says that younger generations are obligated to respect and care for older adults [1]. Respect for older adults based on filial piety has resulted from the emphasis on social relationships and intergenerational hierarchy [2]. However, rapid industrialization and changes in the nuclear family have decreased filial piety in Korea [3]. With the rapid population aging, intergenerational conflicts frequently occur in Korean society [4]. Specifically, with limited resources and health care costs and caregiving expenses for older adults increasing rapidly, they have come to be treated as social burdens [5-7]. As the retirement age for older adults has increased, they stay for longer in the job market, leading younger people to think that older adults are taking up their potential jobs by not retiring [4]. Many younger generations also view older generations negatively because welfare benefits for older generations are better than those for younger generations [4]. Furthermore, older adults view various social issues differently from younger people [7]. As a result, the attitude of younger people toward older adults is negative and intergenerational conflicts have been observed, especially in the labor market $[7,8]$. From the perspective of the swAge model, the negative attitudes of younger workers toward older workers interrupt sustainable working life for people of all ages [9].

To develop an environment where people can participate in society regardless of their age, intergenerational programs have been suggested as the solutions based on the underlying assumption that the biggest cause of intergenerational conflict is the lack of opportunity for younger and older generations to interact [4]. According to Bostrum and 
her colleagues, an intergenerational program could provide the means for the younger and older generations to exchange resources and learn from each other [10]. Intergenerational programs based on contact between generations have been identified as a tool for understanding different generations and changing biases and stereotypes against older adults [11-13]. In Korea, the importance of intergenerational programs was noted during the 1990s and programs that were designed to focus on interaction between grandparents and grandchildren became prevalent in the 2000s [14,15]. Recently, intergenerational programs encouraging mutual understanding were implemented in the third and fourth Basic Government Plans for Low Fertility and Aging Society in Korea, which were established in 2016 and 2021 [7]. At the same time, intergenerational programs became basic programs in senior welfare centers in Korea, emphasizing the importance of information exchange and interaction between generations. These trends emerged in the context of the aging society of Korea in 2017, and it is necessary to build a sustainable society for all ages [4].

Although intergenerational programs are known to bring benefits to younger generations as well as older generations [4,16-19], the perspective that social capital is one of the most important benefits of intergenerational programs has hardly been discussed. This study assumes that social capital contributes to a sustainable working life for older adults and that it is formed when different generations come into contact frequently and work together with the same goals $[20,21]$. However, there is little empirical and theoretical evidence and the premises of these programs have seldom been reported in the literature, except for a few studies [22-24]. This study observed a situation where interaction among different generations shrank in a society; specifically, we observed that younger generations tended to avoid interaction with older generations because of their lack of understanding of older adults [4]. It is advised that intergenerational contact is important in order to generate social capital for both generations. In addition, trust among generations, a type of social capital, is increased by the intensify and duration of contact [25]. The purpose of this study was to explore the impact of an intergenerational program on social capital among younger and older generations to promote a sustainable work environment for various generations.

\section{Literature Reviews}

The swAge model, which represents a sustainable working life for all ages, explains how older adults can attain a healthier working life in a sustainable way [9]. According to the swAge model, the decision to continue work is influenced by nine factors: health, physical work environment, mental work environment, working hours, personal finances, family situations, organizational attitude toward social participation, work satisfaction, and work skill development in employees $[9,26]$. The swAge model also suggests four different categories derived from these nine factors at individual levels: personal health; private economy; social inclusion and participation in a group; and self-fulfillment which is meaningful, stimulating, and creates activities at individual levels $[9,26,27]$. Among these four categories, social inclusion and participation in a group relates to social capital, which enables individuals to mobilize resources and groups of people to have power to strengthen an organization or community [28]. Social capital theory proposes that social capital is formed when different generations contract frequently and work together with the same goals $[20,21]$. Social relationships among generations in any social structure could create social capital, such as trust and social networks [29]. In other words, in a community where several generations form social capital, younger workers have less prejudice against older adults and thus older workers can continually participate in work without discrimination. Work environments without age discrimination can increase the work satisfaction of older workers and encourage them to develop their competence and self-fulfillment, as suggested in the swAge model [9].

The swAge model, therefore, supports the assumption that the mutual understanding and trust created by interaction between older and younger generations is crucial to create a sustainable working life for older adults. In the context, this study focuses on the impact of the intergenerational interaction program on social capital such as trust, 
which will ultimately contribute to build a sustainable working environment for older adults. Bostrom stressed that intergenerational programs had an influence in building social capital and that the social capital of one generation had a spillover effect to other generations [30]. According to Pettigrew in 1998, social capital was built through repeated intergroup contact- that is, frequent contact between different generations created social capital [31]. In general, human beings tend to like establishing companionship, which is a good sign when promoting social capital [32]. While studies dealing with intergenerational program have focused on individual benefits $[16,18,19,33]$, the impact of those programs on social capital has hardly been investigated.

Only a few studies have been conducted to obtain information about gaining social capital through intergenerational exchanges. The REPRINTS program was designed to train older adults to read books to children in schools [21,34]. The results showed that social capital such as trust between the older adults and children in a local community was increased as they administered the ongoing intergenerational programs [21,34]. Different from the previous two studies, Glass in 2004 proposed an intergenerational program called Experience Corps in the community [22]. In this program, social capital at school levels was depicted as the overall school climate changed and parental involvement in school increased, and teacher efficacy was also enhanced [22]. Community building and community development efforts to construct social capital led to build affordable housing, an increase in neighborhood safety, and an improved school environment, which will contribute to reducing poverty and increasing safety in the community [35]. However, previous studies dealing with social capital did not show the perceived social capital of individuals when finishing the intergenerational program [21,22,34]. Most of studies reported that changes in communities occurred after administering those programs, but direct effects were not identified on individuals, which may have been the cause of changes in the community $[21,22,34]$. It is not easy to be certain regarding changes caused by the intergenerational program.

Meanwhile, intergenerational activity studies were conducted in two settings in Manchester, one in primary and secondary schools and the other in families in the community which reported that wellbeing and social capital was enhanced in both settings [36]. Particularly, this previous study focused on younger people and older people gaining insight into self and the other throughout interactions [36]. It has appeared as a process, that is, intergenerational activities have stimulated insight generating wellbeing and social capital. However, the result of enhancing social capital was limited because the previous study in Manchester was conducted not using quantitative assessment but using qualitative assessment [36]. Another case study was conducted by the School Volunteer Program in Western Australia to explore the relationship between intergenerational program and social capital, the study proved that there was potential impact on social capital, not direct impact on social capital [37].

In order to overcome the limitations of previous studies, this study was designed to determine the direct impact of intergenerational program on the perception of trust among intergenerational program participants. Measures of participants' trust in colleagues also reflect their experiences of social support in mental work environment and organizational attitudes under the swAge model [26]. The research hypotheses are as follows:

H1. Intergenerational program will be positively associated with trust in colleagues among older participants.

H2. Intergenerational program will be positively associated with trust in colleagues among younger participants.

\section{Materials and Methods}

\subsection{Proposed Intergenerational Cooperation Program}

The 2019 Sedae Ieum Madang is an intergenerational program in which the young and old generation assess social issues that can easily be sympathized with and seek ways 
to coexist in harmony. The specific goals of the program were to find ways to build a community where various generations can live together without conflict and examine the effects of generational relationships on social capital. To run the program, the Seoul Welfare Foundation and the Ewha Institute for Age Integration Research (EIAIR) at Ewha Womans University worked together to plan tasks, recruit participants, and monitor the participants.

The Sedae Ieum Madang activities consisted of a total of eight sessions, including three collective meetings and five team activities. At the first collective meeting on June 28th, the participants met their team colleagues after being educated about generational coexistence and the Sedae Ieum Madang. There were five teams of six older adults and four to six younger adults in each group. At the second collective meeting on July 19th, the participants watched three short films together about generations and were educated on how to implement Memoro, which is an activity recording interviews of the memories of older adults to pass them on to future generations as a social and cultural heritage $[16,38]$. According to the instructions in Memoro, younger participants recorded the interview of the older colleague's memory and posted it on the Memoro website. On the last meeting held on the 23rd of August, each team proposed a way for generations to coexist in harmony based on their team activities.

Each team met once a week from June 1st to August 9th to discuss the generational conflicts encountered in their daily lives and to seek ways to resolve them. The topics of each team were language differences between generations, information gaps between generations, differences in family culture and perception, generational conflicts in public places, and lack of communication opportunities between generations. Through the team activities, participants were able to understand the perspectives of different generations, and discussed the cause of misunderstandings and ways to reduce conflicts with other generations. For example, the team who dealt with the lack of communication opportunities suggested the lack of physical space to meet each other and the lack of common interests as reasons. Then, they proposed a method of putting a nursing home for older adults and a kindergarten in one place in order to meet naturally and share their interests.

\subsection{Methods}

\subsubsection{Data Collection}

The purposive sampling method was used for the recruitment of participants in this study, as in previous studies about changes in attitudes toward aging $[39,40]$. For the recruitment of younger participants, the Seoul Welfare Foundation and EIAIR promoted the program to universities and youth volunteer groups located in Seoul, and the older participants were recruited through the Korean Association of Retired Persons (KARP) and three senior centers in Seoul (Gandong Senior Welfare Center, Dongjak Senior Welfare Center, and Seoul Senior Welfare Center). It took two months from May to June, 2019, to recruit 56 participants; 30 older adults over 60 and 26 younger adults in their $20 \mathrm{~s}$. In order to induce participation in the program without prejudice, participants who had no similar program experience prior to the intergenerational cooperation activity were recruited [16].

Participants responded the questionnaires with measurement instruments, $20 \mathrm{~min}$ before the first collective meeting (pretest) and $20 \mathrm{~min}$ before the last collective meeting (posttest). The Bioethics and Biosafety Act of Korea requires to receive a review by an institutional review board (IRB). At the same time, the law offers exemption from IRB review requirements to the relevant government ministry and agency which can conclude whether a research proposal is eligible for absolution from IRB review [41]. Since the Seoul Welfare Foundation is a public agency under the Seoul Metropolitan Government, researchers informed the participants that they can withdraw their participation at any time according to their will and that there will be no disadvantages due to their withdrawal. The participants' consent was also obtained for their participation in this research and the use of their personal information to this research according to the bylaw of Seoul Welfare Foundation. 


\subsubsection{Sample}

The final sample size was 53; 30 older adults and 23 younger adults responded to both the pretest and posttest among the initial 56 program participants. The sample characteristics of this study are shown in Table 1 . The average age of the older participants was 73.0 years, and there were more females $(56.7 \%)$ than males $(43.3 \%)$. As for the educational level of older participants, there were a lot of college graduates $(43.3 \%)$ and high school graduates $(43.3 \%)$. More than half of the older participants lived with their grandchildren (53.7\%) and had worked with young people (56.7\%). The number of older participants with experience taking a class about other generation $(23.3 \%)$ was less than the number without experience $(76.7 \%)$. The average age of younger participants was 21 , and they were mostly female (87\%) and attending college (91.3\%). Among the younger participants, there were slightly more who attended classes on other generations or had lived with their grandparents (56.5\%) than those who did not (43.5\%).

Table 1. Sample characteristics $(\mathrm{N}=53)$.

\begin{tabular}{|c|c|c|c|}
\hline \multicolumn{2}{|l|}{ Characteristic } & $\begin{array}{l}\text { Older Adults } \\
\quad(\mathrm{n}=30)\end{array}$ & $\begin{array}{l}\text { Younger Adults } \\
\quad(n=23)\end{array}$ \\
\hline \multicolumn{2}{|l|}{ Mean age, Years (SD) } & $73(6.3)$ & $21(2.3)$ \\
\hline \multirow[t]{2}{*}{ Gender } & Female (\%) & $17(56.7)$ & $20(87.0)$ \\
\hline & Male (\%) & $13(43.3)$ & $3(13.0)$ \\
\hline \multirow[t]{4}{*}{ Education } & ES (\%) & $1(3.3)$ & \\
\hline & MS (\%) & $3(10.0)$ & \\
\hline & HS (\%) & $13(43.3)$ & $21(91.3)$ \\
\hline & College (\%) & $13(43.3)$ & $2(8.7)$ \\
\hline \multirow{2}{*}{$\begin{array}{c}\text { Experience } \\
\text { in having lived with } \\
\text { grandchildren/ } \\
\text { grandparents }\end{array}$} & Yes & $17(53.7)$ & $13(56.5)$ \\
\hline & No & $13(43.3)$ & $10(43.5)$ \\
\hline \multirow{2}{*}{$\begin{array}{l}\text { Experience in program with other } \\
\text { generations }\end{array}$} & Yes & $17(56.7)$ & $20(87.0)$ \\
\hline & No & $13(43.3)$ & $3(13.0)$ \\
\hline Experience & Yes & $7(23.3)$ & $13(56.5)$ \\
\hline taking a class about other generations & No & $23(76.7)$ & $10(43.5)$ \\
\hline
\end{tabular}

Note. SD: standard deviation; ES: elementary school; MS: middle school; HS: high school.

\subsubsection{Instruments}

In order to verify the effect of the intergenerational cooperation program, this study focused on before and after the participation in terms of social capital. To measure changes in social capital, this study selected questionnaires, especially on trust and cooperation, which is one of four subindexes of the social capital scale with network connectivity, setting and sharing of vision, reciprocal norm, trust and cooperation, and group participation [42]. Participants answered to 4 items of trust and cooperation using a 5-point Likert scale (i.e., 1-strongly disagree, 5- strongly agree) [42].

\subsubsection{Data Analysis}

This study designed a group pretest-posttest and employed a paired-samples $t$ test based on the results of literature search about measuring the changes in perceptions toward the other generations $[16,39,40]$. The result of calculation using the mean and standard deviation of the paired differences within two generation groups showed the sample size of this study suitable for applying a paired-samples $t$ test [43]. Additionally, Cohens' $d$ statistic calculated by the pooled mean and divided by the standard deviation for examining effect sizes of independent samples $t$ test [44]. IBM SPSS 24.0 was used for analyzing statistical data. 


\section{Results}

Following the intergenerational cooperation, Table 2 shows that the activity significantly influenced the older participants' rating on all four items in the scale of trust. The older participants' trust increased $(t=-3.09, p<0.01)$ after the cooperation activity with younger participants. The value of Cohen's $d$ proved a medium effect size $(0.40<d<0.66$, $\mathrm{M}(d)=0.54)$. The older participants came to believe that the level of trust $(\mathrm{t}=-1.98, p<0.10)$ and interest increased $(\mathrm{t}=-2.64, p<0.05)$ after taking part in a cooperation activity with younger participants. The older participants began acknowledging the other participants' efforts compared to before the intergenerational cooperation activities $(t=-3.00, p<0.01)$. The older participants' belief that their colleagues would help each other even if issues other than team assignments occurred was greater than that before becoming involved in the intergenerational program $(\mathrm{t}=-2.09, p<0.05)$.

Table 2. Pre-posttest results for older participants' trust in colleagues $(\mathrm{N}=30)$.

\begin{tabular}{|c|c|c|c|c|}
\hline Items & Questionnaire & $\begin{array}{l}M_{1}(S D) \\
M_{2}(S D)\end{array}$ & $\begin{array}{c}\text { PMD (SD) } \\
{[95 \% \mathrm{CI}]}\end{array}$ & $\begin{array}{l}\text { t-Statistic, } \\
\text { Effect Size }\end{array}$ \\
\hline & (All) & $\begin{array}{l}4.03(0.82) \\
4.47(0.58)\end{array}$ & $\begin{array}{c}-0.43(0.14) \\
{[-0.72,-0.15]}\end{array}$ & $\begin{array}{c}\mathrm{t}(29)=-3.09 * * \\
d=0.61\end{array}$ \\
\hline 1 & $\begin{array}{l}\text { My colleagues in my team trust } \\
\text { each other's intentions } \\
\text { and actions. }\end{array}$ & $\begin{array}{l}4.10(0.89) \\
4.43(0.77)\end{array}$ & $\begin{array}{c}-0.33(0.92) \\
{[-0.68,0.11]}\end{array}$ & $\begin{array}{c}\mathrm{t}(29)=-1.98+ \\
d=0.40\end{array}$ \\
\hline 2 & $\begin{array}{l}\text { My colleagues show a high level } \\
\text { of empathy and interest toward } \\
\text { each other. }\end{array}$ & $\begin{array}{l}4.03(0.72) \\
4.13(0.82)\end{array}$ & $\begin{array}{c}-0.10(0.90) \\
{[-0.33,0.39]}\end{array}$ & $\begin{aligned} \mathrm{t}(29) & =-2.64 * \\
d & =0.61\end{aligned}$ \\
\hline 3 & $\begin{array}{l}\text { My colleagues receive all the } \\
\text { recognition they have put in } \\
\text { their work. }\end{array}$ & $\begin{array}{l}4.00(0.91) \\
4.53(0.68)\end{array}$ & $\begin{array}{c}-0.53(0.97) \\
{[-0.90,-0.17]}\end{array}$ & $\begin{array}{c}\mathrm{t}(29)=-3.00^{* *} \\
d=0.66\end{array}$ \\
\hline 4 & $\begin{array}{l}\text { My colleagues help each other } \\
\text { even with issues that are not } \\
\text { related to the team's task. }\end{array}$ & $\begin{array}{l}4.00(1.05) \\
4.43(0.68)\end{array}$ & $\begin{array}{c}-0.43(1.14) \\
{[-0.86,-0.01]}\end{array}$ & $\begin{aligned} \mathrm{t}(29) & =-2.09 * \\
d & =0.49\end{aligned}$ \\
\hline
\end{tabular}

Note. M: mean; $\mathrm{M}_{1}$ : mean of pretest; $\mathrm{M}_{2}$ : mean of posttest; PMD: paired mean differences; $\mathrm{CI}$ : confidential interval (lower limit, upper limit); effect size: Cohen's $d$ (N/A means homogeneity of variance was not assumed); SD: standard deviation; $t$ tests are two-tailed. $+: p<0.10, *: p<0.05,{ }^{* *}: p<0.01$.

Table 3 shows that the changes in younger participants were different from those in the older participants. After the program activity, the average trust shown toward other members among the younger participants decreased slightly, but was not statistically significant. These results might be due to generational differences in expected roles when they work together [4]. For example, throughout the activities, younger participants performed more tasks and roles than the older participants. Younger participants could think that older participants were free-riders as the younger participants took on the burdensome tasks, while the older participants thought that the younger participants were good at their work. 
Table 3. Pre-posttest results for younger participants' trust in colleagues $(\mathrm{N}=23)$.

\begin{tabular}{|c|c|c|c|c|}
\hline Items & Questionnaire & $\begin{array}{l}M_{1}(S D) \\
M_{2}(S D)\end{array}$ & $\begin{array}{c}\text { PMD (SD) } \\
{[95 \% \mathrm{CI}]}\end{array}$ & $\begin{array}{l}\text { t-Statistic, } \\
\text { Effect Size }\end{array}$ \\
\hline & (All) & $\begin{array}{l}4.28(0.68) \\
4.25(0.46)\end{array}$ & $\begin{array}{c}0.33(0.21) \\
{[-0.41,0.48]}\end{array}$ & $\begin{array}{c}t(22)=0.15 \\
d=0.04\end{array}$ \\
\hline 1 & $\begin{array}{l}\text { My colleagues in my team trust } \\
\text { each other's intentions and actions. }\end{array}$ & $\begin{array}{l}4.17(0.78) \\
4.26(0.92)\end{array}$ & $\begin{array}{c}-0.87(0.27) \\
{[-0.64,0.47]}\end{array}$ & $\begin{array}{c}\mathrm{t}(22)=-0.33 \\
d=0.11\end{array}$ \\
\hline 2 & $\begin{array}{l}\text { My colleagues show a high level of } \\
\text { empathy and interest toward } \\
\text { each other. }\end{array}$ & $\begin{array}{l}4.43(0.73) \\
4.30(0.93)\end{array}$ & $\begin{array}{c}0.13(0.25) \\
{[-0.40,0.66]}\end{array}$ & $\begin{array}{c}\mathrm{t}(22)=0.51 \\
d=0.16\end{array}$ \\
\hline 3 & $\begin{array}{l}\text { My colleagues receive all the } \\
\text { recognition they have put in } \\
\text { their work. }\end{array}$ & $\begin{array}{l}4.39(0.72) \\
4.35(0.57)\end{array}$ & $\begin{array}{c}0.04(0.18) \\
{[-0.34,0.42]}\end{array}$ & $\begin{array}{c}t(22)=0.24 \\
d=0.61\end{array}$ \\
\hline 4 & $\begin{array}{l}\text { My colleagues help each other even } \\
\text { with issues that are not related to } \\
\text { the team's task. }\end{array}$ & $\begin{array}{l}4.13(0.87) \\
4.09(1.41)\end{array}$ & $\begin{array}{c}0.04(0.26) \\
{[-0.49,0.57]}\end{array}$ & $\begin{array}{c}\mathrm{t}(22)=0.17 \\
d=0.04\end{array}$ \\
\hline
\end{tabular}

Note. M: mean; $\mathrm{M}_{1}$ : mean of pretest; $\mathrm{M}_{2}$ : mean of posttest; PMD: paired mean differences; CI: confidential interval (lower limit, upper limit); effect size: Cohen's $d$ (N/A means homogeneity of variance was not assumed); SD: standard deviation. $t$ tests are two-tailed.

\section{Discussion}

\subsection{Implications}

This study is meaningful in that it verified the effect of the intergenerational program on individual participants' social capital, such as trust in colleagues, and suggested ideas to build a sustainable work environment for generations in Korea from the aspects of the swAge model. The goal of this study is to verify the impact of the intergenerational program on 53 participants' trust in their colleagues using one of the subscales to measure social capital. Each item is related to experiences of social supports in working groups and social environment of the swAge model [26]. The intergenerational program, Sedae Ieum Madang, consisted of group activities where two generations discuss the realities and alternatives of generational conflicts together. A pretest/posttest design was used with the analysis of paired-sample $t$ test. The main result of this study is that 30 older participants' trust in colleagues improved, but the trust in colleagues for the 23 younger participants did not show statistically significant changes. According to these findings, only the first hypothesis that the intergenerational program would have a positive effect on older generation's trust in colleagues was accepted; the second hypothesis that the intergenerational program would have a positive effect on younger generation's trust in colleagues was rejected.

The most interesting finding of this study is that only older participants experienced an increase in trust toward their colleagues. This result is consistent with that of previous research on social capital, in that social capital increases with age $[45,46]$. However, studies that focused on intergenerational programs mainly found positive changes in younger participants, with the effects of intergenerational contact encouraging a positive perception of the older generation and intergenerational solidarity $[4,16,38]$. After participating in the intergenerational program, why did the perception of the older generation change, who had no change in their perceptions toward other generations and intergenerational solidarity, and who experienced positive changes in social capital? While working with the younger generation, older participants used technology such as the internet or statistics software to increase their understanding of social issues and to think of realistic solutions [4]. In the view of the swAge model, older participants worked at creating a good mental environment and received social support from their younger colleagues [9,26]. In contrast, younger participants were efficient in their work and did not need help from their colleagues compared to the older generation. In other words, younger participants worked in a poor mental environment without support from their older colleagues. Although filial 
piety decreases [3], unilateral and unconditional support from younger participants to older participants might be triggered by the Confucian ethic in Korean culture. While performing tasks, younger participants might also regard older participants as dependent, not independent colleagues.

The results of this study show that the social inclusion of older adults in the workplace can be possible when older workers are also part of creating a good mental environment for younger colleagues. Activities in which younger and older generations cooperate with each other and find alternatives to social issues can be an opportunity to understand one another and have an effect on reducing the younger generation's negative stereotype of older adults $[4,13,16,21,34,38,47,48]$. However, the younger generation's trust in the older generation as working partners did not increase. This result proves the importance of the 4 th micro level of the swAge model, feeling self-fulfillment through meaningful, stimulating, and creative activities [9]. In order to create a sustainable work environment for all generations, the most important thing is to have the capacity to recognize each other as trusted colleagues and to share roles as equals and perform tasks that meet their capacity. To build trust among colleagues, there is no need to be equipped with cutting-edge technology nor years of experience. With basic work skills, younger and older generations can both play a role that they can perform well. A good mental work environment without stress and threats [26] can be developed when all generations support each other. In particular, older generations should realize that organizational culture has changed, unlike when they were young, younger generations can be given specific roles, and hierarchical relationships can be shifted to a flat organizational structure.

\subsection{Limitations}

The limitations of this study should be noted. First, this study has limitations, as it used only one subindex of trust in colleagues for measuring social capital. In addition, the intergenerational program dealt with in this study focused on social issues that the younger and older generations have common interest in, not on the tasks dealt with in workplaces. There is also a limit to the representativeness of the sample, as the sample size was relatively small. In addition, there was no control group included. The effect of the program was tested on participants living in a specific country. The outcomes of the study should not be generalized, as the sample sizes were small and location limited to one country. Much more research will be needed to cover all working ages and cultures.

This study suggests that following research secures a bigger and broader sample from diverse cultural backgrounds and generations in order to validate its findings. It is necessary to develop a program and curriculum that allows older generations to look at the younger generations from a new perspective in a changing society. It is also necessary to reflect the characteristics and positions of various generations to increase social capital for all ages in the work environment. When future researchers design an intergenerational program, older participants can demonstrate their strengths and achieve self-fulfillment based on the meso level of the swAge model [9]. It is also important to verify whether the program helps various generations to achieve a common goal based on mutual trust in workplaces.

\section{Conclusions}

In conclusion, the social burden caused by the extension of lifespan and the increase in the ageing population are not only Korean issues, but also global issues [27]. Many countries are searching for ways to delay retirement because of social expenditure [26]. From the perspective of the swAge model, the intergenerational program would be an effective tool to promote social inclusion and participation in a group, increasing younger generations' understanding of the older generation and reducing age discrimination in the collaborative process between younger and older generations $[4,9,38]$. This study offers clear evidence that intergenerational programs can improve the older generation's trust in younger colleagues, while the younger generation's trust in their older colleagues will 
increase when colleagues support each other. These results provide new directions to build a work environment based on trust and respect toward each other, regardless of age. In order to reduce discrimination toward older workers, employers or policy makers need to encourage various generations to interact equally and naturally. At the same time, political and social support for continuous capacity development as people age is also needed. Empirical research to develop various models of intergenerational programs for different national or organizational cultures should be carried out.

Author Contributions: Conceptualization, S.C.; methodology, J.K.; software, J.K.; validation, J.K.; formal analysis, J.K.; investigation, J.K.; resources, S.C.; data curation, J.K.; writing—original draft preparation, J.K. and S.C.; writing - review and editing, J.K.; visualization, J.K.; supervision, S.C.; project administration, J.K.; funding acquisition, S.C. All authors have read and agreed to the published version of the manuscript.

Funding: This research was funded by the National Research Foundation of Korea, grant number NRF-2020S1A5C2A03092919.

Institutional Review Board Statement: Since the Seoul Welfare Foundation is the agency under the Seoul Metropolitan Government, ethical review and approval were waived for this study according to the Bioethics and Biosafety Act of Korea.

Informed Consent Statement: Informed consent was obtained from all participants in the study.

Data Availability Statement: Data sharing not applicable.

Conflicts of Interest: The authors declare no conflict of interest. The funder had no role in the design of the study; in the collection, analyses, or interpretation of data; in the writing of the manuscript; or in the decision to publish the results.

\section{References}

1. Lew, S.-C.; Choi, W.-Y.; Wang, H.S. Confucian Ethics and the Spirit of Capitalism in Korea: The Significance of Filial Piety. J. East Asian Stud. 2011, 11, 171-196. [CrossRef]

2. Ingersoll-Dayton, B.; Saengtienchai, C. Respect for the Elderly in Asia: Stability and Change. Int. J. Aging Hum. Dev. 1999, 48, 113-130. [CrossRef]

3. Choi, Y. Foundations of Intergenerational Solidarity in Korea. Korean J. Popul. Stud. 2014, 37, 61-87.

4. Kim, J.; Chung, S. A Mixed Method Research on Changing Perceptions of Intergenerational Relations in Senior Policy Monitoring Group Project. Korean J. Soc. Welf. 2019, 71, 177-201.

5. Walker, A. The Economic 'burden' of Ageing and the Prospect of Intergenerational Conflict. Ageing Soc. 1990, 10, 377-396. [CrossRef]

6. Nortey, S.T.; Aryeetey, G.C.; Aikins, M.; Amendah, D.; Nonvignon, J. Economic Burden of Family Caregiving for Elderly Population in Southern Ghana: The Case of a Periurban District. Int. J. Equity Health 2017, 16, 16. [CrossRef]

7. Chung, S.; Lee, S.; Park, M.; Shin, B.; Kim, J. Areas and Causes of Intergenerational Conflict Between Age Groups Based on Expert Delphi Survey. Korean J. Soc. Welf. 2021, 73, 229-253. [CrossRef]

8. Choi, Y.; Oh, Y.; Moon, Y. College Students' Perceptions on Older Generations: Focusing on Intergenerational Conflict, the Elderly's Contribution and Welfare Policies for the Elderly in Korea. J. Korea Contents Assoc. 2015, 15, 228-241. [CrossRef]

9. Nilsson, K. A Sustainable Working Life for All Ages-The SwAge-Model. Appl. Ergon. 2020, 86, 103082. [CrossRef]

10. Bostrum, A.-K.; Hatton-Yeo, A.; Ohsako, T.; Sawano, Y. A General Assessment of IP Initiatives in the Countries Involved. In Intergenerational Programmes: Public Policy and Research Implication: An International Perspective; Hatton-Yeo, A., Ohsako, T., Eds.; UNESCO Institute for Education: Hamburg, Germany, 2000; pp. 3-8.

11. Dionigi, R.A. Stereotypes of Aging: Their Effects on the Health of Older Adults. J. Geriatr. 2015, 2015, 954027. [CrossRef]

12. Granville, G. A Review of Intergenerational Practice in the UK; Beth Johnson Foundation: Staffordshire, England, 2002; ISBN 0-907875-24-6.

13. Martins, T.; Midão, L.; Martínez Veiga, S.; Dequech, L.; Busse, G.; Bertram, M.; McDonald, A.; Gilliland, G.; Orte, C.; Vives, M.; et al. Intergenerational Programs Review: Study Design and Characteristics of Intervention, Outcomes, and Effectiveness: Research. J. Intergener. Relatsh. 2019, 17, 93-109. [CrossRef]

14. Lee, G. A Study on the Strategies in Planning and Implementing Intergenerational Programs: Through Comparative Study of Attitudes toward Older Persons among Generations. J. Welf. Aged 2004, 26, 143-164.

15. Han, G.; Hong, J. Intergenerational Social Support Exchange and Psychological Well-Being of the Elderly. Fam. Cult. 2000, 12, $55-80$.

16. Chung, S.; Kim, J. The Effects of Intergenerational Program on Solidarity and Perception to Other Generations in Korea. J. Soc. Serv. Res. 2021, 47, 219-231. [CrossRef] 
17. Blieszner, R.; Artale, L.M. Benefits of Intergenerational Service-Learning to Human Services Majors. Educ. Gerontol. 2001, 27, 71-87. [CrossRef]

18. Blais, S.; McCleary, L.; Garcia, L.; Robitaille, A. Examining the Benefits of Intergenerational Volunteering in Long-Term Care: A Review of the Literature. J. Intergener. Relatsh. 2017, 15, 258-272. [CrossRef]

19. Cohen-Mansfield, J.; Jensen, B. Intergenerational Programs in Schools: Prevalence and Perceptions of Impact. J. Appl. Gerontol. 2017, 36, 254-276. [CrossRef]

20. Jarrott, S.E.; Smith, C.L. The Complement of Research and Theory in Practice: Contact Theory at Work Jin Nonfamilial Intergenerational Programs. Gerontologist 2011, 51, 112-121. [CrossRef]

21. Murayama, Y.; Murayama, H.; Hasebe, M.; Yamaguchi, J.; Fujiwara, Y. The Impact of Intergenerational Programs on Social Capital in Japan: A Randomized Population-Based Cross-Sectional Study. BMC Public Health 2019, 19, 156. [CrossRef]

22. Glass, T.A.; Freedman, M.; Carlson, M.C.; Hill, J.; Frick, K.D.; Ialongo, N.; McGill, S.; Rebok, G.W.; Seeman, T.; Tielsch, J.M.; et al. Experience Corps: Design of an Intergenerational Program to Boost Social Capital and Promote the Health of an Aging Society. J. Urban Health 2004, 81, 94-105. [CrossRef]

23. Holtgrave, P.L.; Norrick, C.; Teufel, J.; Gilbert, P. Building Community and Social Capital by Engaging Capacity Building Volunteers in Intergenerational Programs. J. Intergener. Relatsh. 2014, 12, 192-196. [CrossRef]

24. Murayama, Y.; Ohba, H.; Yasunaga, M.; Nonaka, K.; Takeuchi, R.; Nishi, M.; Sakuma, N.; Uchida, H.; Shinkai, S.; Fujiwara, Y. The Effect of Intergenerational Programs on the Mental Health of Elderly Adults. Aging Ment. Health 2015, 19, 306-314. [CrossRef]

25. Bekkers, R.; Volker, B.; van der Gaag, M.; Flap, H. Social Networks of Participants in Voluntary Associations. In Social Capital: An International Research Program; Lin, N., Erikson, B., Eds.; Oxford University Press: New York, NY, USA, 2008; pp. $185-205$.

26. Nilsson, K. Conceptualisation of Ageing in Relation to Factors of Importance for Extending Working Life-A Review. Scand. J. Public Health 2016, 44, 490-505. [CrossRef] [PubMed]

27. Nilsson, K. Active and Healthy Ageing at Work-A Qualitative Study with Employees 55-63 Years and their Managers. Open J. Soc. Sci. 2017, 5, 13-29. [CrossRef]

28. Bourdieu, P. The Forms of Capital. In Handbook of Theory and Research of Sociology of Education; Richardson, J.G., Ed.; Greenwood Press: New York, NY, USA, 1986; pp. 241-258.

29. Coleman, J.S. Foundation of Social Theory; Harvard University Press: Cambridge, MA, USA, 1990.

30. Bostrom, A. Lifelong Learning, Intergenerational Learning and Social Capital: From Theory to Practice; Institute of International Education, Stockholm University: Stockholm, Sweden, 2003; ISBN 91-7265-571-2.

31. Pettigrew, T.F. Intergroup Contact Theory. Annu. Rev. Psychol. 1998, 49, 65-85. [CrossRef] [PubMed]

32. Savage, J.; Kanazawa, S. Social Capital, Crime, and Human Nature. J. Contemp. Crim. Justice 2002, 18, 188-211. [CrossRef]

33. Chua, P.H.; Jung, Y.; Lwin, M.O.; Theng, Y.L. Let's Play Together: Effects of Video-Game Play on Intergenerational Perceptions among Youth and Elderly Participants. Comput. Hum. Behav. 2013, 29, 2303-2311. [CrossRef]

34. Fujiwara, Y.; Murayama, Y.; Hasebe, M.; Yamaguchi, J.; Yasunaga, M.; Nonaka, K.; Murayama, H. Influence of Intergenerational Programs on Social Capital in Local Community. Innov. Aging 2017, 1, 214. [CrossRef]

35. Cattell, V. Poor People, Poor Places, and Poor Health: The Mediating Role of Social Networks and Social Capital. Soc. Sci. Med. 2001, 52, 1501-1516. [CrossRef]

36. Kagan, C.; Micallef, A.-M.; Siddiquee, A.; Fatimilehin, I.; Hassan, A.; de Santis, C.; Ali, R.; Williams, T.Z.; Bunn, G. Intergenerational Work, Social Capital and Wellbeing. Glob. J. Community Psychol. Pract. 2012, 3, 8.

37. Cumming-Potvin, W.M.; MacCallum, J.A. Intergenerational Practice: Mentoring and Social Capital for Twenty-First Century Communities of Practice. McGill J. Educ. 2011, 45, 305-323. [CrossRef]

38. Chung, S.; Kim, J.; Hong, Y. The Effects of Bilateral Intergenerational Program on Intergenerational Perceptions of the Participants. J. Intergener. Relatsh. 2021, 19, 56-77. [CrossRef]

39. Kim, J.; Lee, J.; Sims, O.T. The Productive Aging Concept and Social Work Students' Perceptions Toward an Older Population. J. Soc. Serv. Res. 2017, 43, 149-155. [CrossRef]

40. Leedahl, S.N.; Brasher, M.S.; LoBuono, D.L.; Wood, B.M.; Estus, E.L. Reducing Ageism: Changes in Students' Attitudes after Participation in an Intergenerational Reverse Mentoring Program. Sustainability 2020, 12, 6870. [CrossRef]

41. Lee, W.B.; Kee, K. Interpretation of the IRB Review Exemption under the Bioethics and Biosafety Act \& Proposal for Improvement in Practice. Bioethics 2019, 20, 63-82.

42. Moon, Y.-J. A Study on the Construction and Application of Social Capital Scale in Social Welfare Organizations. Korean J. Soc. Welf. Stud. 2011, 42, 381-407.

43. Dhand, N.K.; Khatkar, M.S. Sample Size Calculator for Comparing Two Paired Means. Statulaor. 2014. Available online: https:/ / statulator.com/SampleSize/ss2PM.html (accessed on 20 November 2021).

44. Macgowan, M.J.; Vakharia, S.P. Teaching Standards-Based Group Work Competencies to Social Work Students: An Empirical Examination. Res. Soc. Work Pract. 2012, 22, 380-388. [CrossRef]

45. Chung, S.; Lee, H.; Choi, H.; Lee, E.; Lee, G. Relationship among Social Capital and Human Capital and Cognitive Belief: A Comparison of the Elderly and Different Age Groups. Res. Stud. 2013, 14, 113-142.

46. McDonald, S.; Mair, C.A. Social Capital across the Life Course: Age and Gendered Patterns of Network Resources. Sociol. Forum 2010, 25, 335-359. [CrossRef] 
47. Bai, X. Development and Validation of a Multidimensional Intergenerational Relationship Quality Scale for Aging Chinese Parents. Gerontologist 2018, 58, E338-E348. [CrossRef]

48. Heyman, J.C.; Gutheil, I.A. They Touch Our Hearts: The Experiences of Shared Site Intergenerational Program Participants. J. Intergener. Relatsh. 2008, 6, 397-412. [CrossRef] 